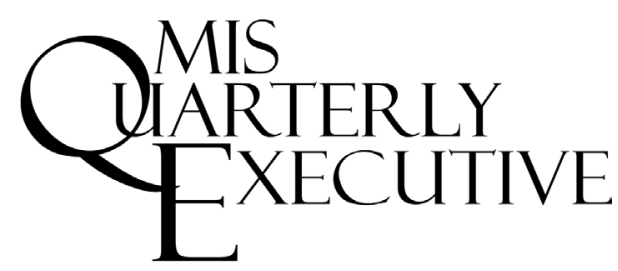

\title{
Driving Process Innovation with loT Field Data
}

The Internet of Things (IoT) promises to deliver tremendous business value and disrupt various industries. However, many companies are taking much longer than anticipated to realize these opportunities. To exploit the digital data streams flowing from their smart, connected products (IoT field data), companies need to identify new opportunities that go beyond well-known product and service innovations. We describe how manufacturing companies are leveraging IoT field data to innovate in their internal processes at all stages of the product lifecycle. ${ }^{1,2}$

Dominik Bilgeri

ETH Zürich (Switzerland)

Heiko Gebauer

University of St. Gallen (Switzerland)
Elgar Fleisch

ETH Zürich and University of St. Gallen

(Switzerland)

Felix Wortmann

University of St. Gallen (Switzerland)

\section{IoT Field Data Can Be Leveraged throughout the Product Lifecycle}

Across all industries, smart, connected products-such as connected cars, smart home appliances, smart fitness trackers and connected drilling machines-are altering how manufacturing companies interact with their customers and ultimately how they conduct business. This new generation of offerings results from the merger of the physical and digital worlds, often referred to as the Internet of Things (IoT). IoT solutions involve equipping physical objects and devices with sensors, actuators, and connectivity, and applying data analytics to the digital data streams (DDSs) flowing from the devices to offer complementary digital services. ${ }^{3}$ The DDSs provide real-time data on usage and device behavior, as well as on environmental parameters. ${ }^{4}$

Figure 1 shows there are four areas (domains) where IoT digital data streams can be used for innovation. These four domains are determined by the DDS source (supply-chain data or field data) and the focus of innovation (product/service or process). Manufacturing companies' early initiatives to benefit from IoT field data focused mainly on offering new digital services

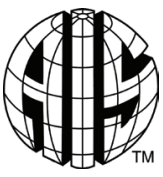

1 Gabriele Piccoli is the accepting senior editor for this article.

2 The authors thank the 46 practitioners who participated in this study for providing interesting insights. Thanks also to Gabriele Piccoli, and two anonymous reviewers, and to Professor Stefan H. Thomke (Harvard Business School), Timo Gessmann (Bosch Digital Solutions) and Dr. Jannis Beese (SAP) for their valuable input and constructive feedback. This research was supported by the Bosch IoT Lab at the University of St. Gallen, and ETH Zurich.

3 For an introduction to the IoT, see Wortmann, F. and Flüchter, K. "Internet of Things - Technology and Value Added," Business \& Information Systems Engineering (57:3), 2015, pp. 221-224.

4 For an overview of digital data streams, see: Piccoli, G. and Pigni, F. "Harvesting External Data: The Potential of Digital Data Streams," MIS Quarterly Executive (12:1), March 2013, pp. 53-64. 


\section{Figure 1: Four Domains Leveraging IoT Digital Data Stream}

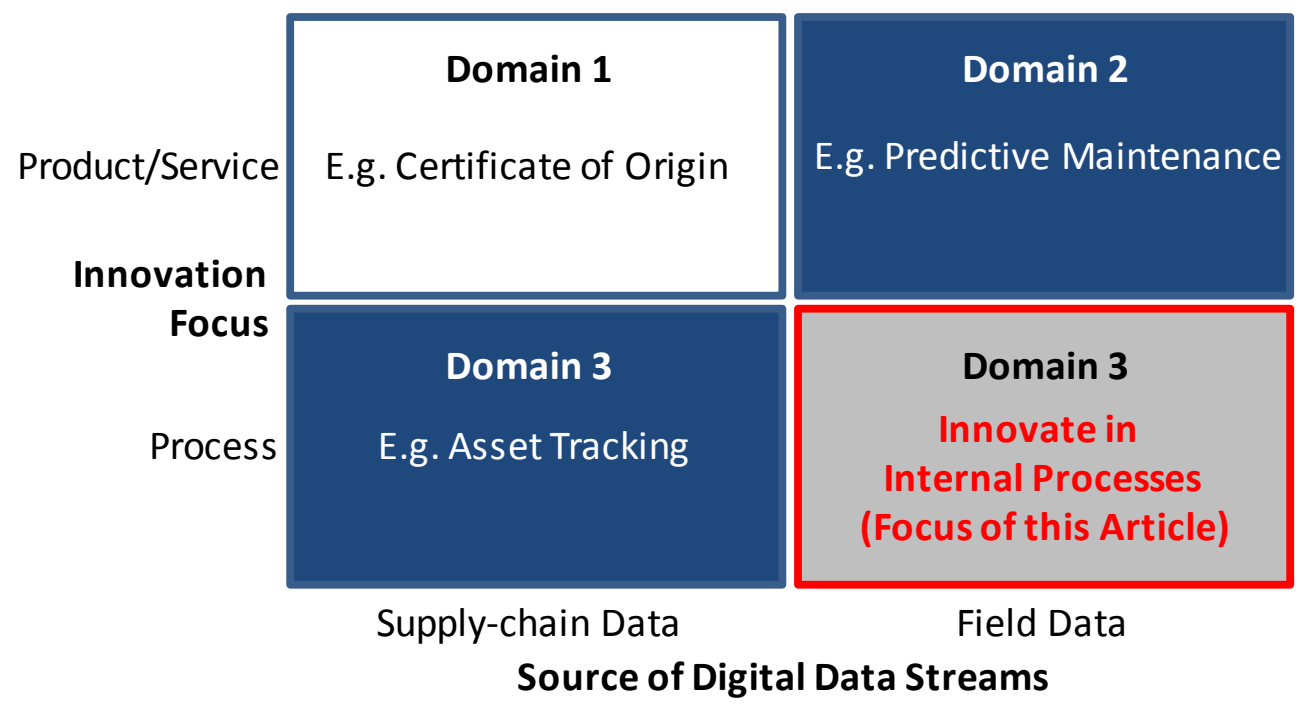

such as predictive maintenance ${ }^{5}$ (Domain 2) and on using supply chain data to drive process innovation such as asset tracking (Domain 3). Now, though, manufacturing companies are pursuing objectives that go beyond their initial digital services (Domains 1 and 4). In particular, they are aiming to leverage the potential of IoT field data to innovate in internal processes-for example, data-driven product specification. These initiatives fall into Domain 4 and are the focus of our research and this article. (The research we conducted is described in Appendix 2.)

DDSs can provide unprecedented levels of insight into products' performance in use, and this insight and visibility can be leveraged throughout the four stages of the product lifecycle to innovate in internal processes (see Figure 2). Stage 1 (Development) is followed by the production and shipment stage (Production and Logistics), marketing and sales stage (Marketing and Sales), and finally by after-sales support and service aimed at selling additional (digital) service components (Support and Service). ${ }^{6}$

Four examples illustrate how major manufacturers are using DDSs at each of the

\footnotetext{
5 For more information, see Ives, B., Palese, B. and Rodriguez, J. "Enhancing Customer Service through the Internet of Things and Digital Data Streams," MIS Quarterly Executive (15:4), December 2016, pp. 279-297.

6 For an introduction to the concepts of product lifecycle, see Saaksvuori, A. and Immonen, A. Product Lifecycle Management, Springer-Verlag Berlin Heidelberg, 2008.
}

four lifecycle stages. At the Development stage, Tesla uses the large amounts of data on drivers' behavior gathered via its connected cars to improve its development processes. Boeing uses the connected sensors embedded in its aircraft to drive the efficiency of factories and supply chains (Production and Logistics stage). German printing machinery manufacturer Heidelberger Druckmaschinen AG (referred to as Heidelberger Druck) gathers data on print jobs and machine usage to conduct market research (Marketing and Sales stage). GE's connected wind turbines gather real-time insights into each turbine's condition, which enables GE to improve its service efficiency (Support and Service stage).

Regrettably, examples such as these are often presented online and in blogs, frequently in the context of promoting dedicated software solutions, and do not provide any details or critical reflection. Our study, however, carefully investigated how manufacturing companies can take advantage of the opportunities provided by gathering and exploiting IoT field data. In this article, we described eight use cases of companies using DDSs for innovation at each of the four stages of the product lifecycle. Table 1 summarizes the use cases and case companies. It shows that we identified two areas of innovation for each of the four lifecycle stages and we illustrate each area with two use cases. The eight use cases are described in Appendix 1. 
Figure 2: Leveraging DDSs throughout the Product Lifecycle

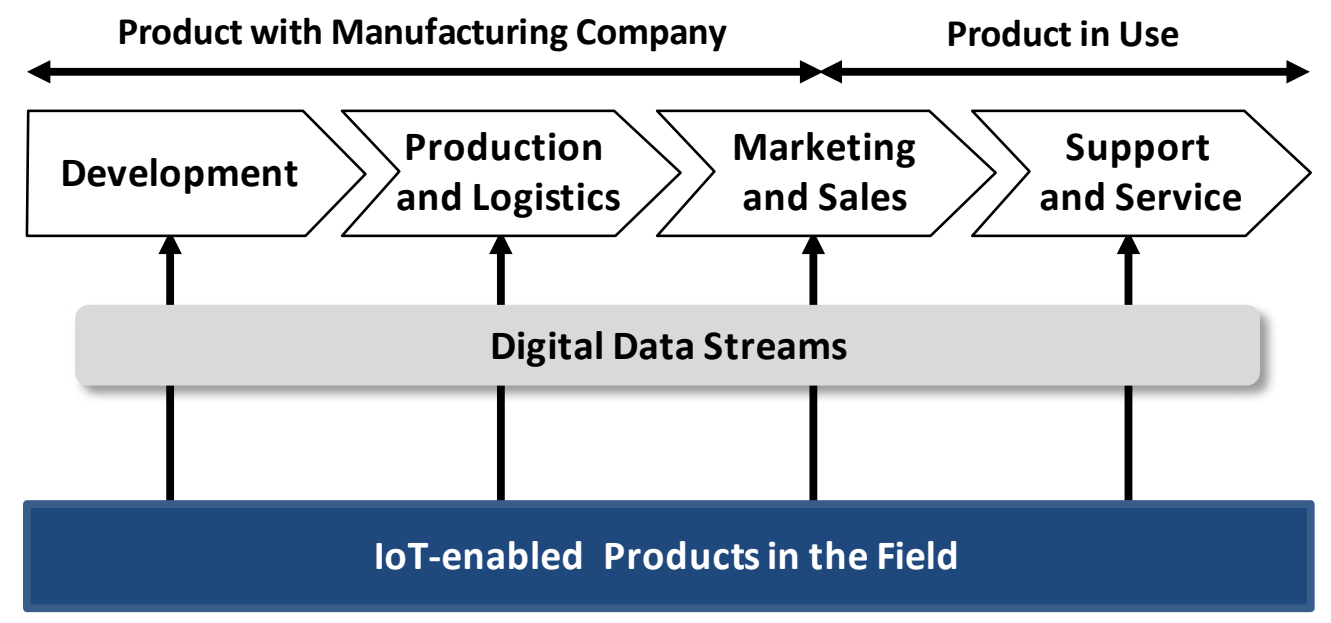

\section{DDS-Driven Innovation at the Development Stage of the Product Lifecycle}

During the Development stage of the product lifecycle, manufacturers design, develop and validate IoT solutions before scaling up production. Specifically, they formulate innovative ideas, define the specifications and the requirements of solutions, build prototypes, and test and validate them.

Historically, manufacturing companies have adopted IT solutions such as CAD (computer-aided design) when developing new products, and have benefited from digitization and simulation efforts, though not always successfully. ${ }^{7}$ In addition, many manufacturers have implemented new innovation approaches such as Design Thinking and Lean Startup. For instance, many now use iterative cycles to benefit from early information, to verify assumptions quickly, and to reduce time to market. More recently, DDSs have provided completely new means of feedback and a valuable source of early information, fueling iterative innovation processes. We have identified two major areas where IoT field data can be exploited at the Development stage of the product lifecycledata2spec and accelerated validation.

\footnotetext{
7 See, for example, Thomke, S. "High-Tech Tools Won't Automatically Improve Your Operations," Harvard Business Review, June 10, 2015, available at https://hbr.org/2015/06/new-technology-wontautomatically-improve-your-operations.
}

\section{Data2spec-Defining Product Specifications Based on IoT Field Data}

Data2spec refers to how manufacturers use IoT field data to optimize product specifications. German automotive supplier Bosch uses operational IoT field data, such as device state, usage, and failure information, to define (technical) product specifications for its connected brake systems. Initially, the data was collected manually by Bosch employees plugging in a diagnostic tool, from vehicle fleet data, or data from customers' irregular visits to repair shops. Now, however, improvements in connectivity allow Bosch to shift from infrequent manual data collection to highly frequent, automated field data collection (e.g., once per day) with an unprecedented level of detail. This enables Bosch to gain knowledge about drivers' usage behavior as well as the stresses and strains on brakes in the field. The DDS from brakes allows Bosch to better understand whether the assumptions it makes on brake requirements are correct and thus helps to avoid costly under- and overspecification of its brake systems.

Another example is provided by Heidelberger Druck, which continuously collects data on the number and frequency of errors in its printing machines and on customers' usage behavior. This data enables Heidelberger Druck to innovate in its product development processes. Many other manufacturing companies have created solutions that leverage IoT field data to prioritize features in their development pipelines. 
Table 1: Summary of Innovation Areas and Use Cases

\begin{tabular}{|c|c|c|c|}
\hline $\begin{array}{l}\text { Lifecycle } \\
\text { Stage }\end{array}$ & $\begin{array}{c}\text { Innovation } \\
\text { Area }\end{array}$ & Description & Use Case \\
\hline \multirow{2}{*}{ Development } & $\begin{array}{l}\text { Data to } \\
\text { specification } \\
\text { (data2spec) }\end{array}$ & $\begin{array}{c}\text { Operational loT field data such as device } \\
\text { state and usage or failure information } \\
\text { is used to define (technical) product } \\
\text { specifications. }\end{array}$ & $\begin{array}{l}\text { Bosch Chassis Control: } \\
\text { Specification of connected brakes }\end{array}$ \\
\hline & $\begin{array}{l}\text { Accelerated } \\
\text { validation }\end{array}$ & $\begin{array}{l}\text { IoT field data and remote software } \\
\text { updates in prototypes and field devices } \\
\text { are used to accelerate and enhance } \\
\text { product validation. }\end{array}$ & $\begin{array}{l}\text { Konecranes: Virtual validation of } \\
\text { smart cranes }\end{array}$ \\
\hline \multirow{2}{*}{$\begin{array}{l}\text { Production } \\
\text { and Logistics }\end{array}$} & $\begin{array}{l}\text { loT root cause } \\
\text { identification }\end{array}$ & $\begin{array}{c}\text { DDSs from loT field devices are leveraged } \\
\text { to identify fundamental challenges in the } \\
\text { production process of products. }\end{array}$ & $\begin{array}{l}\text { Toyota Motors Inc.: Car field data } \\
\text { used to optimize production }\end{array}$ \\
\hline & $\begin{array}{l}\text { Customize and } \\
\text { calibrate }\end{array}$ & $\begin{array}{l}\text { IoT field data enables the optimization or } \\
\text { customization of production processes } \\
\text { and of products. }\end{array}$ & $\begin{array}{l}\text { Bosch Heating Systems: } \\
\text { Customized production processes }\end{array}$ \\
\hline \multirow{2}{*}{$\begin{array}{l}\text { Marketing } \\
\text { and Sales }\end{array}$} & $\begin{array}{l}\text { loT data-driven } \\
\text { market research }\end{array}$ & $\begin{array}{l}\text { IoT field data enables manufacturers } \\
\text { to conduct their own complementary } \\
\text { market research and to learn more about } \\
\text { customers' preferences. }\end{array}$ & $\begin{array}{l}\text { Heidelberger Druck: Sales lead } \\
\text { generation }\end{array}$ \\
\hline & Digital targeting & $\begin{array}{c}\text { Identification of customer segments, } \\
\text { which use solutions for different } \\
\text { purposes and have varying expectations } \\
\text { and preferences. }\end{array}$ & $\begin{array}{l}\text { Procter \& Gamble: Using loT field } \\
\text { data for market segmentation }\end{array}$ \\
\hline \multirow{2}{*}{$\begin{array}{l}\text { Support and } \\
\text { Service }\end{array}$} & $\begin{array}{l}\text { Digitized } \\
\text { warranty } \\
\text { business }\end{array}$ & $\begin{array}{l}\text { IoT field data enables manufacturers } \\
\text { to reduce inefficiencies related to the } \\
\text { analyses and physical shipment of } \\
\text { warranty cases. }\end{array}$ & $\begin{array}{c}\text { Bosch Heating Systems: } \\
\text { Improving the warranty claims } \\
\text { process }\end{array}$ \\
\hline & $\begin{array}{l}\text { Data-driven } \\
\text { service } \\
\text { efficiency }\end{array}$ & $\begin{array}{l}\text { IoT DDSs enable the improvement } \\
\text { of service efficiency-e.g., increase } \\
\text { communication quality or minimize } \\
\text { overall downtime. }\end{array}$ & $\begin{array}{c}\text { Heidelberger Druck: Predictive } \\
\text { monitoring to identify future } \\
\text { equipment faults }\end{array}$ \\
\hline
\end{tabular}

\section{Accelerated Validation-Using IoT Field Data to Accelerate Validation Processes}

With accelerated validation, manufacturers leverage IoT field data to speed up development time by automating their product validation efforts. The data from IoT solutions is used to verify and advance the virtual testing models that manufacturing companies use in their development processes. For example, Finnish industrial crane manufacturer Konecranes uses IoT field data in combination with remote updating of software and configurations in prototypes and field devices to accelerate and enhance product validation. In collaboration with Siemens AG, Konecranes built a cloud-based digital twin of its industrial cranes and lifting equipment and used IoT field data to evaluate the models' assumptions.

\section{DDS-Driven Innovation at the Production and Logistics Stage of the Product Lifecycle}

The second product lifecycle stage covers manufacturing companies' production processes, including activities performed to transform raw materials or to assemble acquired components into higher-value outputs. Logistics processes are part of this product lifecycle stage. 
Hitherto, manufacturers have put tremendous efforts into digitizing and automating their production and logistics systems. However, few of the related use cases have used field data as an input for innovation in production and logistics processes. To demonstrate how IoT data can be leveraged to improve production efficiency, we have identified two major areas where DDSs can be exploited-IoT root cause identification and customize and calibrate.

\section{IoT Root Cause Identification- Optimizing Production Processes with IoT DDSs}

Once the frequency of certain error messages, collected by sensors in connected products, reaches a predetermined threshold, manufacturers can react quickly and identify underlying root causes of the errors. Toyota, for example, is leveraging DDSs from IoT field devices to identify fundamental challenges in its production processes. The IoT field data is used not only to improve Toyota's internal production processes but can also be extended to suppliers and the components they provide. In cases of severe quality issues, poorly performing suppliers can be identified more efficiently, and immediate measures can be taken to mitigate existing problems.

\section{Customize and Calibrate-Optimizing Last Production Steps with loT Field Data}

Customize and calibrate refers to the final adjustments of production processes as well as adjustments made to products before they leave the production line and are shipped to customers. These adjustments might include a final quality assessment procedure or setting specific product default parameters to meet particular environmental conditions at customer sites. IoT field data on usage behavior and failure rates enables manufacturing companies to improve these final production steps. For instance, Bosch Heating Systems uses IoT field data to optimize, or even customize, the quality-control and product-configuration procedures within its production processes. Specifically, the company aims to implement an automated feedback loop that provides error notifications from connected products, and to use this feedback to adapt its final quality assessment process. Usually, such initiatives start with irregular reports from downstream supply chain partners and are automated only at a later point in time. Bosch's long-term goal is to use the automated feedback to continuously adjust its calibration activities.

\section{DDS-Driven Innovation at the Marketing and Sales Stage of the Product Lifecycle}

Manufacturing companies perform a variety of processes in the Marketing and Sales stage of the product lifecycle. These processes position their products in attractive markets, segment those markets according to different customer types, communicate the added value of a product, and manage the distribution channels and sales force needed to sell their products. Another major task during this stage is planning and executing pricing strategies across market segments and sales channels.

For decades, manufacturers have relied on information from market research companies (such as Gartner, GfK, and Nielsen) to assess (potential) markets. They have also relied on historic data or market surveys (either inhouse or conducted by research firms) to better understand their markets. The DDSs now flowing from IoT devices offer manufacturing companies a new means to segment their markets, target individual customers, and generate sales leads. We have identified two major areas of DDS use in the Marketing and Sales stage of the product lifecycle-IoT data-driven market research and digital targeting.

\section{IoT Data-Driven Market Research- Data-Driven Market Intelligence and Consulting}

IoT data-driven market research provides manufacturers with the ability to complement existing market research offerings with their own industry- and company-specific insights. For example, Heidelberger Druck leverages IoT data to identify promising customers for add-on solutions. This initiative enables the company to improve its sales efficiency and increase the quality of communication with customers. Such an approach allows manufacturing companies to increase the efficiency of customer acquisition 
processes and to optimize investments in their technology and product pipeline. The insights gained will enable companies to improve their sales employees' ability to address customers' real concerns and needs and increase the prospects-to-sales conversion rate.

\section{Digital Targeting-Leveraging IoT Field Data to Segment the Market}

With digital targeting, manufacturing companies can segment the market based on actual usage behavior observed via IoT devices rather than on assumptions, surveys, or field studies. This approach ensures a far more accurate differentiation of customers that enables two fundamental value propositions. First, DDSs are expected to provide a better overall understanding of what kind of market segments exist in reality. Second, the data allows for a more accurate allocation of a particular customer to an identified segment. For example, U.S. consumer goods company Procter \& Gamble (P\&G) intends to use IoT field data from its Oral-B smart toothbrushes to identify and individually target customer needs and to market complementary products. Initially, P\&G has used the DDS generated by its smart toothbrushes to learn more about customers' brushing behavior and to offer value by providing customers with feedback. Next, the company aims to derive higher resolution market data with the ambition of building on the IoT data to sell additional products.

\section{DDS-Driven Innovation at the Support and Service Stage of the Product Lifecycle}

In the final Support and Service stage of the product lifecycle, manufacturing companies perform a variety of processes after they have sold their products. They usually offer customers maintenance and spare parts services (e.g., via repair shops), run help centers to provide support for customers across sales channels, and try to sell additional add-ons and complementary services and solutions. Examples of the latter include insurance, maintenance, financing options, and warranties. The two major uses of DDSs we identified in this final stage of the product lifecycle are digitized warranty business and data-driven service efficiency.

\section{Digitized Warranty Business-Reducing Inefficiencies of Support Processes}

DDSs can be exploited by manufacturers to digitize their warranty business, which is one of their support processes. Warranty processes, either required by regulators or compelled by market forces, are usually cumbersome and lowvalue manual activities. In the past, for example, if customers experienced a problem with a Bosch Heating Systems product, they would contact local service engineers who would then analyze their heating systems. Repairs often meant changing a specific component. Now, IoT field data allows Bosch to gather a variety of data, including product, environmental, and behavioral data, and thus to reduce inefficiencies resulting from a lack of direct customer contact.

The IoT field data also allows Bosch Heating Systems to gain a much deeper understanding of the circumstances of specific, malfunctioning components. Previously, it was very difficult to identify patterns in the occurrence of certain errors. Once IoT data on the wear and tear of heating systems in the field is broadly available, including the average heating temperature and heating behavior, this data might be used to support error-detection patterns and to gain a better understanding of the conditions under which certain warranty-relevant problems arise.

\section{Data-Driven Service Efficiency- Improving Internal Service Efficiency}

Data-driven service efficiency is another major area where IoT field data can be used in the Support and Service stage of the product lifecycle. Service processes are typically characterized by a high level of costly and labor-intensive activities. The main potential for exploiting DDSs in service processes lies in the automation of communication, remote monitoring, error detection, and remote maintenance, as well as in empowering customers to perform part of the value creation. For example, Heidelberger Druck uses DDSs to improve service efficiency, increase the quality of customer communications, and extend its products' lifespans, while minimizing overall machine downtime. Hence, this manufacturer of printing machinery benefits 
Figure 3: DDS Evolutionary Paths for Each Product Lifecycle Stage

\begin{tabular}{|c|c|c|c|c|}
\hline & Step 1 & Step 2 & Step 3 & Step 4 \\
\hline $\begin{array}{c}\text { Stage 1: } \\
\text { Development }\end{array}$ & $\begin{array}{l}\text { Automated } \\
\text { data collection }\end{array}$ & $\begin{array}{l}\text { From test labs } \\
\text { to field devices }\end{array}$ & $\begin{array}{l}\text { Over-the-air } \\
\text { updates }\end{array}$ & $\begin{array}{l}\text { Developing } \\
\text { products digitally }\end{array}$ \\
\hline $\begin{array}{l}\text { Stage 2: } \\
\text { Production }\end{array}$ & $\begin{array}{l}\text { Product-focused } \\
\text { production insights }\end{array}$ & $\begin{array}{l}\text { Field-aware } \\
\text { production }\end{array}$ & $\begin{array}{l}\text { Customer-specific } \\
\text { production insights }\end{array}$ & $\begin{array}{l}\text { Customer-aware } \\
\text { production }\end{array}$ \\
\hline $\begin{array}{l}\text { Stage 3: } \\
\text { Marketing }\end{array}$ & $\begin{array}{l}\text { Trend and market } \\
\text { insights }\end{array}$ & $\begin{array}{l}\text { Higher resolution } \\
\text { market insights }\end{array}$ & $\begin{array}{l}\text { Customized } \\
\text { marketing }\end{array}$ & $\begin{array}{l}\text { Data-driven } \\
\text { sales }\end{array}$ \\
\hline $\begin{array}{c}\text { Stage 4: } \\
\text { Support } \\
\text { and Service }\end{array}$ & $\begin{array}{l}\text { Integrated support } \\
\text { and services }\end{array}$ & $\begin{array}{l}\text { Increase degree of } \\
\text { process automation }\end{array}$ & $\begin{array}{l}\text { From reactive to } \\
\text { proactive }\end{array}$ & $\begin{array}{l}\text { Customer } \\
\text { empowerment }\end{array}$ \\
\hline
\end{tabular}

from offering new services to its customers, as well as from the ability to streamline its internal processes.

\section{Evolution Paths for Exploiting DDSs}

To realize the full power of IoT field data for internal process innovation, it is crucial to understand the evolutionary paths that the use of DDSs follow within each of the four product lifecycle stages (see Figure 3). The consecutive steps within the evolutionary paths enable manufacturing companies to incrementally gain new capabilities and to advance their leverage of DDSs for internal process innovations over time. ${ }^{8}$

\section{Evolution during the Development Stage}

Both use cases that illustrate the use of DDSs at the Development stage of the product lifecycle followed similar evolutionary paths. These manufacturers started by automating data collection and are currently moving on to integrating test or prototype field devices,

\footnotetext{
8 For a primer on the stepwise evolution of capabilities for harnessing DDSs, see Herterich, M. M., Uebernickel, F. and Brenner, W. "Stepwise Evolution of Capabilities for Harnessing Digital Data Streams in Data-Driven Industrial Services," MIS Quarterly Executive (15:4), December 2016, pp. 297-318.
}

which will be followed by implementing overthe-air two-way communication, and, ultimately, by enabling the virtual (i.e., simulation-based) development of their products.

Step 1: Automated Data Collection. The first step in the Development stage is to automate the collection of real-time data from smart, connected prototype devices (i.e., the data flows from the test device to the manufacturer's development team). Initially, Bosch's Chassis Control business unit collected data manually from the sensors in its brake systems by Bosch employees plugging in a diagnostic tool to extract the data. By providing the IoT devices embedded in the brakes with a wireless connection, Bosch has been able to automate (at least partly) the data collection. However, while providing test or prototype devices with connectivity at this first stage of the product lifecycle is a significant improvement on only carrying out physical tests, the data collected automatically is mainly from test devices or test labs, and only occasionally from customers.

Step 2: From Test Labs to Field Devices. In the second evolutionary step during the Development stage, a manufacturing company extends its data collection efforts from prototypes in test labs to larger "fleets" of devices in the field. However, limited and costly bandwidth can make data transmission expensive, and some 
manufacturers have implemented mechanisms to address this constraint. For instance, a German car manufacturer developed an online tool that different units within the company can use to request data collection from the field. By using an easy-to-configure dashboard, the units "order" data and internally pay for it. This data helps them to improve their development processese.g., for designing the navigation structure of the infotainment system installed in the company's cars.

Step 3: Over-the-Air Updates. The first two evolutionary steps during the Development stage focus on the data flow from devices to developers. In the next step, the manufacturer implements two-way data communication, from developer to device to developer. Two-way communication allows the manufacturer to update test fleets and devices in the field, which decreases timeto-market by shortening development learning cycles. As illustrated by Konecranes, two-way data communication might initially be limited to specific parameters. In this use case, current customers' and supply chain partners' safety concerns militate against a more extensive data exchange.

Step 4: Virtual Development. Once manufacturing companies have gathered sufficient amounts of data from the first three evolutionary steps during the Development stage, new development approaches become feasible, including using smaller test fleets, computer-simulated development procedures, or more data validation. Konecranes' ambition to accelerate its crane development process is a good example of how IoT field data can enable a virtual development process. With a growing base of operational data, Konecranes envisions partly substituting physical engineering (hardwarecentric) with digital (simulation-based) engineering, resulting in increased quality and reduced costs.

\section{Evolution during the Production and Logistics Stage}

Both use cases that illustrate the use of DDSs to innovate at the Production and Logistics stage of the product lifecycle followed a similar four-step evolutionary path, which shifted the focus from product-specific to customer-specific insights.
Step 1: Product-Focused Production Insights. In this first step, the IoT field data is usually product-focused. Ad hoc insights generated from specific problems detected by connected sensors are used to improve manufacturing and logistic processes on a case-by-case basis. For instance, Toyota aims to leverage IoT data on potential field issues to identify root causes in its manufacturing processes and to check manufacturing parameters on an ad hoc basis.

Step 2: Field-Aware Production. In the second evolutionary step during the Production and Logistics stage, the case-specific, ad hoc database improvements made during the first step are systematically transformed into product-focused insights that are incorporated into production processes. Take, for example, Bosch Heating Systems' ambitions to adopt quality controls. While still product-focused, newly (re)designed processes will allow the company to improve efficiency and also enable it to adjust product specifications for all customers.

Step 3: Customer-Specific Production Insights. The more detailed the data that can be collected is, and the more that production can be customized, the more manufacturers will be able to benefit from customer-specific, production optimizations based on usage behavior. One example of this is the calibration of devices-i.e., the ability to change configuration settings of devices for individual customers. In this third evolutionary step during the Production and Logistics stage, however, these adjustments are, again, initially implemented on an ad hoc basis.

Step 4: Customer-Aware Production. The final evolutionary step during the Production and Logistics stage enables the automation of customer- or customer-segment-specific production processes to take account of IoT field data. A good example of customer-aware production and delivery is the ability to deliver products to customers before they place an order, based on their previous consumption. Amazon, which is a leader in this area, calls this ability "anticipatory shipping."

\footnotetext{
9 For a summary of Amazon's anticipatory shipping initiative, see Kopalle, P. "Why Amazon's Anticipatory Shipping Is Pure Genius," Forbes, available at https://www.forbes.com/sites/onmarketing/2014/01/28/why-amazons-anticipatory-shipping-is-puregenius/\#864ba884605e.
} 


\section{Evolution during the Marketing and Sales Stage}

The two use cases that illustrate the use of DDSs to innovate at the Marketing and Sales stage of the product lifecycle both extended the scope of activities from generic market research to improving individual customer interactions.

Step 1: Trend and Market Insights. Initially, IoT field data enables manufacturers to learn more about current and potential markets. These insights allow them to make informed investment decisions and frees them from depending on large research companies such as Gartner, Nielsen, and GfK. Heidelberger Druck's IoT-based market research showed that many customers run shorter print jobs with set-up times of the printing machinery being more important than machine throughput. As a consequence, the company decided to invest in optimizing set-up times.

Step 2: Higher Resolution Market Insights. The second evolutionary step during the Marketing and Sales stage increases the resolution of the market data that manufacturers gather and thus enables them to identify market segments and generate individual sales leads. Using IoT field data for this purpose is more costefficient and more motivating for sales employees than traditional approaches to identifying market segments. IoT field data enables manufacturers to learn about the particular needs of individual customers. ${ }^{10}$ Procter \& Gamble aims to leverage IoT field data to target existing customers for future purchases.

Step 3: Customized Marketing. Once market segments have been identified, IoT field data can be used to align sales channels, marketing campaigns, and promotion activities. Customizing marketing and sales activities informed by DDSs enables manufacturers to significantly increase conversion rates of prospects, as indicated in one of the Heidelberger Druck use cases. This company uses IoT field data to identify potential new sales to existing customers based on their current print order situation and to customize the sales pitches accordingly.

Step 4: Data-Driven Sales. In the final evolutionary step during the Marketing and

10 See, for example, Gilliland, N. "How the beauty industry is embracing the Internet of Things," Econsultancy, January 9, 2017, available at https://econsultancy.com/how-the-beauty-industry-isembracing-the-internet-of-things/.
Sales stage, IoT field data allows manufacturers to conduct industry-wide benchmarking and economic feasibility studies. In the earlier steps, it was possible to benchmark only between internal plants and production lines. The new insights gained during this step enable manufacturers to educate different ecosystem stakeholders and their own salespeople on how best to approach individual market segments.

\section{Evolution during the Support and Service Stage}

The two use cases that illustrate the use of DDSs to innovate during the Support and Service stage of the product lifecycle both started by using IoT field data to provide integrated support and services, moved on to increase the degree of support-process automation, shifting from reactive to proactive, and ultimately aim to empower their customers.

Step 1: Integrated Support and Services. Various stakeholders are involved in providing support and services after the actual sale of a product, and many of these players collect their own IoT field data. Thus, manufacturing companies can benefit from integrated support and services that take into account the DDSs from all the different players, including OEMs, customers, suppliers, and service providers. Bosch Heating Systems not only produces connected heating systems, but also allows customers to register their products online so it can process valid warranty claims more efficiently.

Step 2: Increase the Degree of SupportProcess Automation. Traditional service and support processes usually involve a lot of direct communication with customers and are therefore very labor-intensive and expensive. Once manufacturers have established sufficient DDSs, they can increase the degree of automation of these processes, which helps them reduce process throughput times and increase the overall quality of communication and customer service. Heidelberger Druck provides an additional fee-based service called "e-call" that allows customers to transfer a digital error message directly from a printing machine, leading to a significant reduction of communication time and hence cost. 
Step 3: From Reactive to Proactive Support and Services. In this third evolutionary step during the Support and Services stage, manufacturers use new technologies such as artificial intelligence and machine or deep learning to analyze the unstructured IoT field data to cluster problem sets, predict the most common errors, or more generally gain a deep understanding of the data. The insights from these analyses enable them to create fast, reliable, and cost-efficient service processes that are proactive rather than reactive. For instance, by combining machine data with maintenance records Heidelberger Druck was able to create smart maintenance schedules, which had a positive impact on the trade-off between proactive repair work and machine downtime.

Step 4: Customer Empowerment. In this final evolutionary step, real-time feedback provided by IoT field data and new technologies such as augmented reality enable manufacturers to transfer part of their value creation to their customers. This means that customers are empowered to resolve issues themselves without having to rely on the expertise and presence of the manufacturer's employees. Empowering customers to solve problems themselves reduces costs for both players and also ensures minimum downtime.

\section{Recommended Actions for Driving Process Innovation with loT Field Data}

To leverage IoT field data for process innovation, manufacturing companies first need to implement the technical, legal, and organizational infrastructures to provide their products with the IoT sensors and devices that will generate the DDSs. ${ }^{11}$ As with any complex information systems (IS) initiative, standard IS management practices are needed to realize the initiatives described in this article. Our research, however, has identified four specific recommendations relevant to leveraging IoT field data for process innovation. The recommendations should not be misinterpreted

11 For an overview on how to leverage DDSs, see Pigni, F., Piccoli, G. and Watson, R. "Digital Data Streams: Creating Value from the Real-Time Flow of Big Data," California Management Review (58:3), May 2016, pp. 5-25. as being part of a sequential process or hierarchical model, but rather constitute a set of principles that need to be properly addressed to successfully leverage IoT field data to innovate in internal processes.

\section{Don't Focus Just on "Blockbuster" IoT Initiatives}

IT and business executives need to understand the entire spectrum of new possibilities for process innovation offered by IoT field data. Too often, the term IoT is perceived as being synonymous with a small number of popular and widely reported "blockbuster" initiatives such as predictive maintenance. This narrow view of IoT is problematic for two reasons. First, the focus on blockbuster initiatives often prevents companies from identifying and exploring ways of leveraging IoT field data to innovate in their internal processes. Second, the widely reported IoT initiatives are often advanced and complex, and companies with limited IoT experience that try to implement similar systems will fail and end up frustrated.

To address the first issue, IT and business executives should focus on the entire product lifecycle and use the IoT innovation areas we have identified at each product lifecycle stage as a source of inspiration. However, the DDS initiatives we have described are only the tip of the iceberg, and are by no means exhaustive; there are many more opportunities for driving process innovation with IoT field data. In fact, manufacturing companies can gain even greater benefits by combining different DDSs. To address the second issue-the tendency to focus on overly ambitious and advanced IoT applications-it is crucial that executives are aware of the need to think big and start small.

\section{Address the Digital Paradox by Thinking Big, Starting Small}

Previous research has found that most IoT initiatives are not meeting management expectations and fail to cover the initial expenses invested. This phenomenon is referred to as "the digital paradox"12 and highlights that even with good intentions and favorable conditions,

12 For more on the digital paradox, see Gebauer, H., Fleisch, E., Lamprecht, C. and Wortmann, F. "Overcoming the Digitalization Paradox: Growth Paths for Digitalization," Business Horizon, 2020 (forthcoming). 
IoT initiatives may well fail. To address the digital paradox, IT and business executives should not scale back their IoT ambitions, but should be aware it will not be easy to implement IoT initiatives. Successfully leveraging IoT field data for process innovation requires considerable resources and expertise. Even large manufacturers such as GE have struggled with their IoT initiatives. ${ }^{13}$ The challenge for top management is to think big-i.e., to develop and communicate a clear vision of how the company aims to leverage DDSs-but start small. Implementing process innovations incrementally, step by step, along the evolutionary paths identified in this article will allow manufacturing companies to sustainably build up the required capabilities and structures over time.

\section{Provide Sufficient Value to Earn Your Customers' Trust and to Increase their Willingness to Share Data}

To increase their customers' willingness to share data, manufacturers need to implement state-of-the-art data security and privacy mechanisms to make their IoT-based offerings trustworthy. ${ }^{14}$ In addition, our findings show that to incentivize the exchange of data, manufacturers have to demonstrate that they provide sufficient value to their customers. A clear and effective communications strategy is key for demonstrating the value provided. Customers want to know how they will benefit from process innovations driven by IoT field data. Potential benefits might include lower prices resulting from efficiency gains, greater convenience, extended warranty periods enabled by higher quality, or new service offerings.

Moreover, privacy and security concerns are not restricted to individuals. The Konecranes use case is one of several examples that indicate these concerns are important for business-tobusiness (B2B) customers. Awareness of these issues among B2B customers is being raised by the current political debates on privacy breaches

13 See Davenport, T. H. and Westerman, G. "Why So Many HighProfile Digital Transformations Fail," Harvard Business Review, March 9, 2018, available at https://hbr.org/2018/03/why-so-manyhigh-profile-digital-transformations-fail.

14 For an overview on IoT privacy and security challenges, see Lowry, P. B., Dinev, T. and Willison, R. "Why Security and Privacy Research Lies at the Centre of the Information Systems (IS) Artefact: Proposing A Bold Research Agenda," European Journal of Information Systems (26:6), November 2017, pp. 546-563. at large social media networks and by the introduction of new data protection regulations, such as the General Data Protection Regulation (GDPR) in Europe. Manufacturing companies should proactively address the potential legal and emotional obstacles that might hinder the collection of IoT field data from the ever-growing population of smart, connected devices.

\section{Recognize that the IT Function Won't Have the Capabilities to Implement IoT Initiatives}

IT practitioners have espoused the concept of bimodal IT (also known as two-speed IT), ${ }^{15}$ which distinguishes between two main types of IT required for a digital transformation. With the first type, traditional IT focuses on the operation of the core business, ensuring integrated, efficient and reliable business processes. The second type empathizes with end users and provides easy-touse and hassle-free digital solutions that address customers' needs. However, IoT initiatives are more complex and require new capabilities that go beyond the scope of established bimodal IT practices. Specifically, IoT initiatives require the integration of a third type of IT capabilityembedded IT (i.e., embedding computing devices in physical objects to make them smart and providing them with connectivity).

Companies will also need to establish data analytics capabilities so they can turn large volumes of often time-series-based usage and device data into actionable insights. Most manufacturing companies have little experience in analyzing large amounts of time-series-based (device) data, and they will need to build up resources from scratch. There are two common approaches to acquiring the required capabilities.

The first approach is to establish a new IoT unit that integrates core IoT resources in an early phase of the digital transformation in order to concentrate IoT activities and gain initial momentum. Bosch's Chassis Control business unit collaborated closely with Bosch Software Innovations to implement its connected brakes initiative. This software innovations unit is dedicated to supporting IoT DDS initiatives for various business units across Bosch. This

15 For an explanation of bimodal IT, see Haffke, I., Kalgovas, B. and Benlian, A. "Options for Transforming the IT Function Using Bimodal IT," MIS Quarterly Executive (16:2), June 2017, pp. 101-120. 
software innovations unit is dedicated to supporting IoT DDS initiatives for various business units across Bosch.

The second approach is to introduce governance mechanisms for managing companywide IoT activities. For example, the newly founded Heidelberg Digital Unit at Heidelberger Druck coordinates the company's activities to leverage IoT field data for both the development of new services and internal process innovation.

\section{Concluding Comments}

The digital data streams that flow from smart, connected products allow manufacturers to generate unprecedented business insights. In this article, we presented our findings derived from analyzing how manufacturing companies are leveraging IoT field data to innovate in their internal processes at all four stages of the product lifecycle. We also described how the use of IoT field data evolves incrementally during each of the lifecycle stages. Based on our findings, we provide recommended actions for how manufacturing companies can leverage IoT field data to innovate in their internal processes as part of their digital transformation efforts.

However, there are some limitations to our findings. The use cases are a convenience sample-the selection of participating companies and their representatives was opportunistic and small. Although the selection restricted our ability to generalize, our close relationships with the companies concerned allowed us to obtain rich stories and in-depth data on IoT field data initiatives. The IoT applications and use cases described in this article represent recent and still ongoing flagship initiatives by major global manufacturing companies, including Bosch, Heidelberger Druck, Procter \& Gamble, Toyota, and Konecranes. A second limitation is that the innovation areas we identified and described are by no means exhaustive, and further research is required on how IoT field data can be used to drive process innovation. In fact, we hope that our research will provide a fruitful foundation for further studies.

\section{Appendix 1: Case Descriptions}

The eight use cases described below (and referenced throughout the article) illustrate how manufacturers are leveraging IoT field data at different stages of the product lifecycle. Three of these use cases come from two divisions of one company (Bosch) and two come from Heidelberger Druck, a German printing machinery manufacturer. Two of the use cases relate to the Development stage of the product lifecycle, two to the Production and Logistics stage, two to the Sales and Marketing stage and two to the Support and Service stage.

\section{Use Cases at the Development Stage of the Product Lifecycle}

1. Bosch-Using IoT Field Data to Determine Requirements for Connected Brakes. A decade ago, German automotive supplier Bosch started to collect digital data streams derived from its brakes, which Bosch had equipped with various electronic sensors. Bosch's aim was to improve the efficiency of its development processes.

First, Bosch equipped its smart brakes with connectivity, which enabled it to automatically

\section{Figure 4: Illustrative Example of Data Analysis at Bosch ${ }^{16}$}

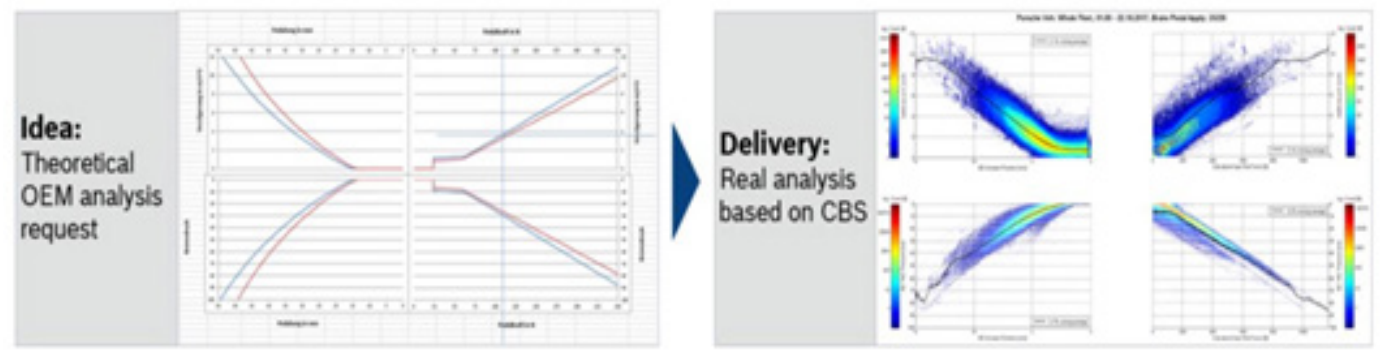

16 Source: Bosch Software Innovations Webinar, 2018. 
gather and analyze data from its brake products (see figure above). The data was collected either via the back-end infrastructure of individual car manufacturing companies (OEMs) or directly by Bosch. However, at this stage, the automated data flow was unidirectional, flowing from the brakes to Bosch product development personnel.

Bosch is now implementing a bi-directional data flow, which will allow it to remotely update the firmware of test vehicles. This ability shortens development cycles. Previously, if developers testing a new configuration of parameters realized they needed to adjust a specific test metric, they would have had to adjust the parameters manually.

Bosch now constantly adjusts its requirements' definition process to make the best use of new insights gained from analyzing IoT field data. For instance, quantifying the reduced hydraulic load in a particular car model allowed Bosch to use an "as is" existing brake system, rather than modifying the system as recommended by existing validation models, which were based on assumed loads.

2. Konecranes-Using IoT Field Data to Improve the Efficiency of the Crane Validation Process. Before the implementation of cloudbased systems and IoT connectivity, the different systems involved in Finish industrial crane manufacturer Konecranes' validation activities were not connected, and data collection was partly manual.

First, the company built "digital twins" (databased models) of its physical cranes to improve its validation processes in test labs. These digital twins were based on data collected from multiple sensors attached to physical, smart cranes. According to Konecranes' Chief Digital Officer, "With an integrated digital twin platform, we see major potential in speeding up the product development process, reducing prototypes, increasing traceability, and thus improving quality and reducing development cost."17

Konecranes is now extending its digital data stream source from test lab prototypes to live products in the field. In the near future, it aims

17 From "Konecranes Adopts Internet of Things Technology to Bridge virtual and Real Worlds Using Siemens' Digital Innovation Platform," Cision News, January 10, 2019, available at https:// news.cision.com/inmema-pr/r/konecranes-adopts-internet-ofthings-technology-to-bridge-virtual-and-real-worlds-using-siemens-dig,c2714067. to be able to remotely update cranes in the field. However, such two-way communication will only be implemented on a small scale and for specific parameters, in light of customers' and supply chain partners' concerns about safety and external security threats.

Konecranes' engineers aim to leverage IoT field data further to improve the company's development processes. They emphasize the power of digital twins to complement physical prototypes and to improve the efficiency of the crane validation process.

\section{Use Cases at the Production and Logistics Stage of the Product Lifecycle}

3. Toyota-Leveraging IoT Field Data for Efficient Root Cause Identification. Toyota uses a data communication module (DCM) in its vehicles to gather field data for the Toyota Smart Center, which uses the collected big data to improve internal processes. In addition, Toyota's Mobility Service Platform processes the collected data for new services models, including ride- and car-sharing operators, insurance companies, and governmental services. ${ }^{18}$ An example of process improvement, relating to the optimization of quality controls in manufacturing was provided by Jeff Makarewicz, Toyota's Group Vice President for Quality and Safety Engineering:

"So, for example, in the future, if we do have a particular field issue, which of course we hope to prevent, we can trace that part back to its manufacturing conditions and try to understand if there is something in the manufacturing process that was out of control or out of specification. And so by doing that we can improve our processes and make them even more robust using Kaizen [continuous improvement]."19

4. Bosch Heating Systems-Leveraging IoT Field Data to Evaluate Quality Controls in the Final Production Stage. Bosch Heating Systems manufactures systems consisting of heat cells and burners. Each system is tested before it leaves the production line. When cleared for shipment, the heating systems are sold to end

18 From Toyota Annual Report, available at https://www.toyotaglobal.com/pages/contents/investors/ir_library/annual/pdf/2017/ ar17_2_en.pdf.

19 From Brown, L. "How IoT and Big Data Improved Toyota's Manufacturing Process," TechRebulic, September 27, 2017, available at https:/www.techrepublic.com/article/how-iot-and-big-data-improved-toyotas-manufacturing-process/. 
customers and installed via third-party sales channels. Specialized assembly mechanics install and maintain the heating systems on customers' premises, and, in the past, these mechanics were the main point of contact with customers. Bosch gathered feedback from the assembly mechanics, leveraging the information to improve quality controls. In a recent initiative, Bosch Heating Systems is currently developing a new solution that connects its systems in the field, which will eventually allow the company to automatically collect and analyze data on error rates. A manager highlighted the benefits of this new solution:

"We currently rely on the goodwill of the mechanics, who inform us irregularly about common error patterns they observe. Connecting our heating systems will allow us to systematically understand what's going on in the field. Hence, we gain useful insights on how effective our quality controls really are." Team Leader, Bosch Heating Systems

Bosch Heating Systems now aims to leverage the data flowing from this new digital data stream to reevaluate its quality control procedures and to adjust the default settings of parameters in its products. This will enable Bosch to better calibrate its heating systems to the needs of its customers and to the conditions at customers' premises.

\section{Use Cases at the Marketing and Sales Stage of the Product Lifecycle}

5. Heidelberger Druck-Using IoT Field Data for Market Intelligence and DataDriven Consulting. Heidelberger Druck is a world-leading manufacturer of sheet-fed printing machines, with the price for a single machine easily ranging in the million euros. It was convinced that the field data collected from its smart, connected machinery would allow it to make the right investment decisions and to identify customers likely to make additional purchases, with the highest benefit coming from purchases of certain add-on solutions.

When analyzing the print market, two key issues are the overall market growth and overall equipment effectiveness (OEE). Maximizing OEE is mission-critical for Heidelberg's customers. Two main factors influence this performance indicator: the printing speed and the make-ready time. Realizing that many customers run shorter print jobs when the make-ready time has more impact than a faster top speed, Heidelberger Druck decided to invest in optimizing make-ready times. Ultimately, customers also benefit from this data-driven investment decision.

In addition, Heidelberger Druck used IoT field data to assess if complementary add-on solutions would be valuable to individual customers. It uses the field data to identify those customers, whobased on their print order situation-would benefit most from an add-on solution. By focusing on this subgroup of customers and customizing the sales pitch to an individual customer's needs, the company has increased the prospects-to-sales conversion rate. Hence, Heidelberger Druck has realized significant cost savings and increased its sales force's motivation.

Finally, Heidelberger Druck is using the DDS to increase the efficiency of its consulting business. IoT field data supports the companies' consultants by creating benchmark reports and enabling the analyses of various industry-relevant KPIs, including the OEE across its customer base (see the figure above).

\section{Figure 5: Illustrative Example of Data Analysis at Heidelberger Druck}
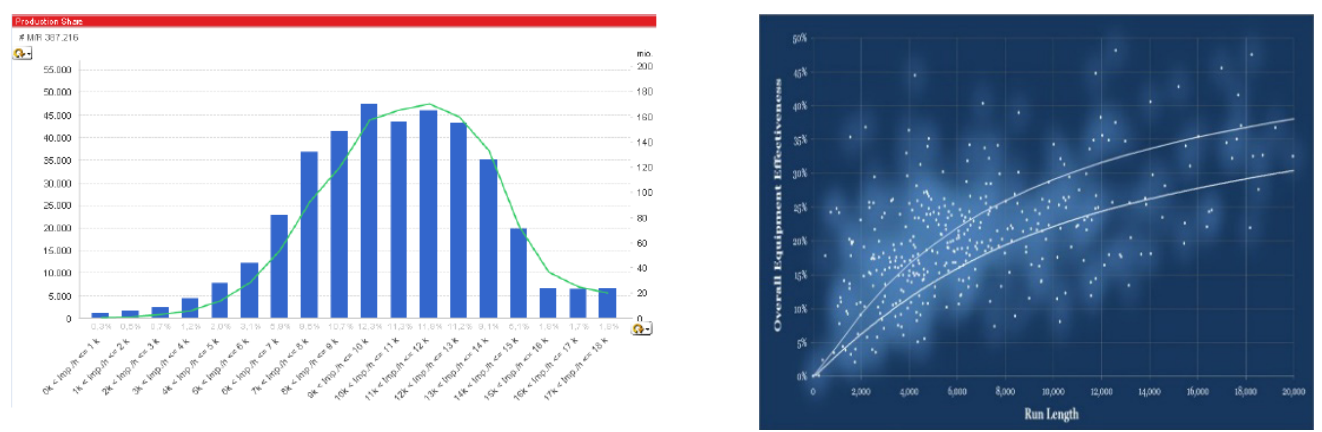
6. Procter \& Gamble-Leveraging IoT Field Data to Target Individual Customers. U.S. consumer goods corporation Procter \& Gamble's (P\&G) Oral-B toothbrush range includes a smart toothbrush. This product facilitates the tracking of brushing behavior, making recommendations on how to improve the cleanness of customers' teeth and enabling customers to share data with their dentists.

P\&G has plans to introduce a new AI-powered Oral-B toothbrush, which will leverage IoT data to analyze a customer's brushing behavior, provide a feedback score, and offer recommendations for improvements. The AI-based product will also allow $\mathrm{P} \& \mathrm{G}$ to "recommend other $P \& G$ products such [as] toothpaste, mouthwash, and dental floss that it thinks would benefit the user, and which they can then go on to buy within the [Oral-B] app. ${ }^{\prime 20} \mathrm{P} \& \mathrm{G}$ is therefore planning to target existing customers for future purchases. A P\&G manager highlighted that in the future the Oral-B brand might move beyond just oral care:

"We want to build a brand that doesn't only stand for the best oral care but goes one step further. We know that [oral health] is the door to the rest of your body. How can we tell you, based on that, how you are doing with the rest of your health? This is our future vision." Giulia Antoniazzi, Global Associate Brand Manager, $P \& G^{21}$

\section{Use Cases at the Support and Service Stage of the Product Lifecycle}

7. Bosch Heating Systems-Leveraging IoT Field Data to Improve the Warranty Claims Process. As part of its warranty business, Bosch Heating Systems needs to check whether warranty claims are justified. If so, it has to interface with its sales partners to receive the customers' data so it can process a claim. In some geographical markets, Bosch is unaware of where its products are eventually installed and located. Hence, even though Bosch cannot inform its customers about potential issues, it is responsible for managing valid warranty claims.

20 Hammett, E. "How Oral B is using AI, Data and Smart Mirrors to Take the Brand Beyond Oral Health," MarketingWeek, February 26, 2019, available at https://www.marketingweek.com/2019/02/26/ oral-b-smart-mirror/.

21 Ibid.
Bosch equips its heating systems with connectivity and allows customers to register their products online (providing incentives such as extending the warranty period). The connectivity and online registration provide the company with data sources it can leverage.

In a next step, Bosch aims to consider production data, such as information about the plant and production line that produced a particular part, and might include production parameters, such as the torsional moments or the applied pressure used to assemble the part. It believes that this type of production data could allow it to change the production of the parts in real time if it detects a problem caused by a specific machine in the production line.

Finally, Bosch Heating Systems intends to implement systematic remote analysis of products in the field, which will generate a deep understanding of how errors relate to malfunctioning components. Once Bosch can perform these diagnostics, it can guide local mechanics even more precisely on how to repair systems by offering very specific instructions.

8. Heidelberger Druck-Leveraging IoT Field Data to Move from Reactive Service to Predictive Monitoring. Heidelberger Druck's printing machines are complex and intensively used, which means that service activities are inevitable and mission-critical. Since 2004, the company has been able to provide its service engineers with information about faults before their first site visit. As a consequence, the firsttime fix rate has increased, and the time to fix has decreased.

In a subsequent development, Heidelberger Druck offered an additional fee-based service called "e-call" that allows a customer's machine to transfer a digital error message directly to the company. This service reduced the time for communicating an error from 30 minutes to 1 minute and resulted in a further cost reduction. Heidelberger Druck is now frequently able to either solve a problem remotely or send an engineer with the required repair parts to the customer.

While this solution improved internal process efficiency significantly, it was still reactive in nature. Heidelberger Druck wanted to be able to detect potential errors in advance, allowing it to schedule maintenance before machines 
experienced unplanned downtimes. However, there is a trade-off between maximum efficient changes and machine downtimes, so the company now incorporates preemptive changes to prevent an error from occurring in existing maintenance schedules. The preemptive maintenance is driven by analyzing IoT field data to evaluate the lifespan of individual parts. At present, the thresholds used to decide whether to replace a part are based on the engineers' experience, but the company is experimenting with AI-based solutions to identify potential future errors.

\section{Research Conducted for this Article}

We followed a three-step procedure to produce the results presented in this article First, over a period of five months (January to May 2018), we conducted a pilot study, exploring potentially interesting companies that were leveraging IoT field data to drive process improvements and possible study participants. The interviews conducted during this step allowed us to gain a deep understanding of the current state of manufacturing industry IoT initiatives and to identify particularly important themes to be discussed. Second, we hosted a two-day workshop with 13 participants from various units of a large manufacturing company to discuss how IoT field data was being leveraged. In the third step (over a period of eight months from July 2018 to February 2019), we conducted another round of 30 expert interviews and a second workshop with three participants to collect data for our use cases. Individual study participants were contacted again to validate our results and confirm the case descriptions and quotes.

We talked to representatives of various manufacturers to validate and complement our findings. All of our interviewees were experienced experts representing different company functions and were capable of providing deep insights into their organizations' current IoT field data initiatives. The interviews were held face-to-face or via phone, and were conducted in English or German, with the authors taking field notes. For six out of the eight use cases, we triangulated the data by interviewing at least two representatives of the manufacturer and by analyzing additional secondary sources, including company documents, online reports, and meeting minutes.

\section{About the Authors}

\section{Dominik Bilgeri}

Dominik Bilgeri (dominik.bilgeri@cemsmail. org) is a Ph.D. candidate at the Bosch IoT Lab at ETH Zurich where he investigates the phenomenon of IoT digital business models. He is particularly interested in data-driven innovation, IoT revenue models, and IoT organizational structures. Dominik was a visiting fellow at Harvard University in the fall of 2018 and holds an M.Sc. from Erasmus University Rotterdam.

\section{Heiko Gebauer}

Heiko Gebauer (Heiko.Gebauer@unisg.ch) heads the "Data Mining and Value Creation" project at the Fraunhofer IMW and works at the Bosch IoT-Lab of the University of St. Gallen. He is also a professor of international and strategic management at Linkoping University. A main focus of his work is investigating three empirical phenomena-service, scaling, and digitization paradoxes-and he has published various articles on these phenomena in academic and management journals. He also actively works as an academic adviser to a variety of companies.

\section{Elgar Fleisch}

Elgar Fleisch (efleisch@ethz.ch) is a professor of information and technology management at ETH Zurich and University of St. Gallen. He and his team aim to understand and design the ongoing merger between the physical and digital worlds. His work focuses on applications, social and economic impacts, and infrastructures of mobile and ubiquitous computing. His research has appeared in several international journals such as Management Science and Nature Energy. Professor Fleisch is a co-founder of several university spin-offs and serves on multiple academic steering committees and management boards.

\section{Felix Wortmann}

Felix Wortmann (Felix.Wortmann@unisg. ch) is an assistant professor of technology management at the University of St. Gallen and the scientific director of the Bosch IoT Lab. His 
research interests include the Internet of Things, blockchain, big data, and digital innovations in mobility, energy, and health. His work has been published in international journals including Journal of the Association for Information Systems, Decision Support Systems, Business \& Information Systems Engineering, Transportation Research Part A, and Transportation Research Part D. Dr. Wortmann also has several years of industry experience in a German-based multinational software corporation. 